\title{
Parathyroid Hormone Responses to Catecholamines and to Changes of Extracellular Calcium in Cows
}

\author{
Juerg W. Blum, Department of Animal Production, Federal Institute of Technology, \\ 8092 Zurich, Switzerland \\ JAN A. FisCHER and Willi H. HunZIKER, Research Laboratory for Calcium \\ Metabolism, Departments of Orthopedic Surgery and Medicine, University, \\ 8008 Zurich, Switzerland \\ U. BINSwANGER, Laboratory of Nephrology, Department of Medicine, University, \\ 8008 Zurich, Switzerland \\ Giovanni B. Picotti and Mosè Da Prada, Pharmaceutical Department, F. Hoffmann- \\ La Roche and Company, Ltd., 4002 Basel, Switzerland \\ AlbiN GuillebeaU, Institute of Veterinary Physiology, University, 8057 Zurich, \\ Switzerland
}

A B S T RACT Modifications of the plasma level of immunoreactive parathyroid hormone (PTH) in cattle were induced by changes of the plasma concentrations of epinephrine, isoproterenol, or calcium.

During abrupt hypocalcemia, PTH, obtained by infusions with ethylene glycol-bis ( $\beta$-aminoethylether) $N, N^{\prime}$-tetraacetate (EGTA), increased during the first 4-8 min. After a transient decline, the hormone levels rose again and remained elevated. Infusions of calcium suppressed the hypocalcemia-induced augmentation of PTH levels within a few minutes. Prolonged epinephrine (and isoproterenol) infusions also rapidly increased PTH levels, however, in this case, they returned to basal concentrations after 50-60 min. Additional epinephrine infusions could not further raise PTH values. Moreover, three short-lasting infusions of epinephrine ( $7 \mathrm{~min}$ each), given at $30-\mathrm{min}$ intervals, increased PTH levels to the same extent, whereas additional infusions were much less effective. The PTH response to epinephrine was completely restored, when the interval after a prolonged epinephrine infusion had been prolonged to $>100 \mathrm{~min}$. During moderate hypocalcemia, occurring at the end of EGTA infusions and lasting for $90 \mathrm{~min}$, the PTH response to a short-lasting epinephrine infusion $(7 \mathrm{~min})$ was more pronounced than in normocalcemic animals. Dur-

This work was presented in part at the 57th Annual Meeting of the Endocrine Society, New York, June 1975 (Abstr. 46) and at the 3rd International Conference on Production Diseases, Wageningen, The Netherlands, September 1976.

Received for publication 27 April 1977 and in revised form 17 October 1977. ing severe hypocalcemia, in which superimposed short-lasting infusions of EGTA $(7 \mathrm{~min})$ led to an additional abrupt fall of plasma calcium concentrations but not to a corresponding additional rise of the PTH levels, epinephrine rapidly and further increased PTH concentrations. On the other hand, at the end of prolonged infusions of epinephrine, when additional infusions of epinephrine were ineffective in raising PTH levels, EGTA-induced hypocalcemia consistently increased PTH concentrations. The EGTA-induced augmentation of PTH levels was enhanced by epinephrine and isoproterenol but not by propranolol.

The present findings indicate, that variations of the extracellular calcium concentrations and $\beta$-adrenergic agonists modify PTH levels by two different and independent mechanisms. On the other hand, it appears that the magnitude of change of the PTH levels to either stimulus is partially modulated by exposure to the other.

\section{INTRODUCTION}

The most important factors regulating parathyroid hormone (PTH) ${ }^{1}$ secretion are the plasma calcium (Ca) and plasma magnesium $(\mathrm{Mg})$ concentrations (1-8). Epinephrine and isoproterenol stimulate the release of PTH in vivo and in vitro in a dose-dependent manner,

\footnotetext{
${ }^{1}$ Abbreviations used in this paper: bPTH, bovine $\mathrm{PTH}$; $\mathrm{Ca}$, plasma calcium; $\mathrm{Ca}^{++}$, ionized plasma calcium; cAMP, cyclic adenosine $3^{\prime}, 5^{\prime}$-monophosphate; EGTA, ethylene glycol-bis( $\beta$-aminoethyl ether)- $N, N^{\prime}$-tetraacetate; $M g$, plasma magnesium; PTH, immunoreactive parathyroid hormone.
} 
and apparently through interaction with $\beta$-adrenergic receptor sites localized on parathyroid cells (9-17).

In the present investigation, modifications of PTH levels, obtained by prolonged infusions of epinephrine and isoproterenol, were compared with the well-known PTH alterations that were induced by changes of the serum calcium concentration, and with additional adrenergic effects such as changes of FFA, glucose, blood pressure, and heart rate (18-20). Because there is evidence for an adrenergic modulation of the secretion of several endocrine glands (21), which causes changes in cyclic $3^{\prime}, 5^{\prime}$-adenosine monophosphate (cAMP), and since calcium regulates adenylyl cyclase and phosphodiesterase activities in several tissues $(22-27)$, we have also studied the action of calcium and $\beta$ adrenergic agonists, given alone or in combination, on PTH levels.

\section{METHODS}

Experimental design. After indwelling catheters had been bilaterally implanted in the jugular vein of cows, the animals were left undisturbed for $\cong 1 \mathrm{~h}$ in the standing position, before blood collection. Blood (15 ml) was collected anaerobically from a jugular vein by a syringe. $10 \mathrm{ml}$ of blood was transferred to a plastic tube containing $50-\mathrm{U}$ (USP) of heparin (Hoffmann-LaRoche Inc., Basel, Switzerland) and after centrifugation at $4^{\circ} \mathrm{C}$, the plasma was separated. Ethylene glycol-bis ( $\beta$-aminoethyl ether) $N, N^{\prime}$ tetraacetate (EGTA)-titrable Ca was measured within $24 \mathrm{~h}$ in unfrozen plasma, whereas plasma samples for the determination of PTH and $\mathrm{Mg}$ were kept frozen at $-20^{\circ} \mathrm{C}$ until assayed. The remaining $5-\mathrm{ml}$ of blood was immediately placed in evacuated glass tubes (Becton, Dickinson \& Co., Rutherford, N. J.), the serum was separated anaerobically after clot retraction and centrifugation, and used for the determination of plasma ionized calcium $\left(\mathrm{Ca}^{++}\right)$. For plasma catecholamine measurements, the heparinized blood was centrifuged at $4^{\circ} \mathrm{C}$ immediately after blood collection and the plasma, transferred to tubes placed on dry ice, was frozen within $2-3 \mathrm{~min}$ and maintained at $-20^{\circ} \mathrm{C}$ until the analyses were performed.

Basal samples (controls) were collected in triplicate at 2-min intervals from a jugular vein. Solutions of EGTA (10\% $\mathrm{wt} / \mathrm{vol}$, adjusted to $\mathrm{pH} 7.4$ with $\mathrm{NaOH}$ ), calcium borogluconate (20\% wt/vol, $1 \mathrm{ml}$ containing $18.6 \mathrm{mg}$ calcium), epinephrine, isoproterenol, or the $\beta$-adrenergic blocker propranolol (dissolved in $0.9 \% \mathrm{NaCl}$ ) were then infused into the contralateral vein by means of peristaltic pumps. Blood samples were obtained according to the schedules described in the different experimental protocols.

In some experiments, the heart rate was electrocardiographically monitored and the blood pressure was measured at 5-min intervals in the left or right superficial temporal artery. The dissection and ligation of the artery was performed after sedation with a tranquilizer and under local anesthesia at least 1 day before the experiments $(28,29)$. The blood pressure was directly recorded (Mingograf, ElemaSchoenander, Stockholm, Sweden) after connection of the intraarterial catheter with a Statham element $(\mathrm{P} 23 \mathrm{Db}$, Hato Rey, Puerto Rico) and an electromanometer (Electronics for Medicine, Inc., White Plains, N. Y.).

Materials. D,L-Propranolol was a gift from Imperial Chemical Industries, Macclesfield, Cheshire, England, L-epinephrine- bitartrate was purchased from Fluka AG, Buchs, Switzerland, and isoproterenol-HCl from Winthrop Products \& Co., Surbiton-on-Thames, England. EGTA was purchased from Sigma Chemical Co., St. Louis, Mo., and calcium borogluconate was prepared by Veterinaria AG, Zurich, Switzerland.

Methods of analysis. Immunoreactive PTH was determined in multiple dilutions in plasma by radioimmunoassay, as previously described $(5,6,9)$. In the present investigations, a different anti-bovine-PTH (anti-bPTH) serum (Goat 10A, day 404) was used at a final concentration of $1: 10,000$. The amounts of purified bPTH-(1-84) Inolex Corp., Biomedical Div., Glenwood, Ill., lot 147865) and of synthetic bPTH-(1-34) (Beckman Instruments, Inc., Palo Alto, Calif.) required for a $50 \%$ inhibition of the binding of ${ }^{131} \mathrm{I}$ bPTH- $(1-84)$ to the antibodies were $0.092 \pm 0.004$ and $50 \mathrm{ng}$, respectively. bPTH-(53-84) (obtained by tryptic digestion of purified bPTH-(1-84) and donated by Dr. Keutmann, Boston, Mass.) was not detectable in amounts of as high as $500 \mathrm{ng}$. This suggests, that the antibodies were mainly directed to determinants located in the middle part of the bPTH-(1-84) molecule. All samples from one experiment were analyzed in the same assay. The intraassay coefficients of variation were up to $10 \%$, the interassay coefficients of variation up to $15 \%$.

Plasma Ca (= EGTA titrable or unchelated), $\mathrm{Ca}^{++}$(ionized fraction of total plasma $\mathrm{Ca}$ ), and $\mathrm{Mg}$ were measured as previously described $(5,6,9)$. Glucose was measured by an enzymatic autoanalyzer method (30) (coefficient of variation $1.5 \%)$ and FFA were determined with a colorimetric micromethod (31). Extraction of FFA from $100 \mu \mathrm{l}$ instead of $50 \mu \mathrm{l}$ plasma, and shaking for $20 \mathrm{~min}$ instead of $90 \mathrm{~s}$, increased the sensitivity of the method (coefficient of variation $3.0 \%$ ). In some experiments, plasma proteins were measured by the biuret reaction (32) (coefficient of variation $1.0 \%$ ). In other experiments catecholamines were determined by a specific radioenzymatic method (33) (coefficient of variation: intraassay $3 \%$, interassay $11 \%$ ).

Basal values of PTH, catecholamines, $\mathrm{Ca}, \mathrm{Mg}$, glucose, FFA, and protein were calculated from the mean of three and $\mathrm{Ca}^{++}$ from the mean of two samples drawn before the start of the different infusions. Acute PTH responses (mean $\Delta 6-8 \mathrm{~min}$ $\mathrm{PTH}$ ) were defined as the mean of the PTH values reached at 6,7 , and 8 min after the start of the infusions minus the mean of the basal values. The $\Delta 6-8 \mathrm{~min}$ PTH responses were related to the levels of the other parameters (mean $\Delta 6-8 \mathrm{~min}$ of $\mathrm{Ca}, \mathrm{Ca}^{++}$, $\mathrm{Mg}$, protein, FFA, glucose, or epinephrine, respectively), measured in the same sample.

Results are expressed as mean $\pm S E$. Statistical analysis was done by paired $t$ test and by regression analysis (34).

\section{RESULTS}

Effect of EGTA-induced hypocalcemia on PTH levels (Fig. 1). In response to hypocalcemia induced by infusions with EGTA (lasting for $120 \mathrm{~min}$ ), PTH increased during the first 4-8 $\mathrm{min}$ (acute response). In spite of the continuous fall of $\mathrm{Ca}$ and $\mathrm{Ca}^{++}, \mathrm{PTH}$ temporarily decreased $(P<0.01)$. Thereafter, PTH levels increased again and remained elevated until the end of the EGTA infusions (late response). When the EGTA infusions were followed by calcium infusions (lasting for $10 \mathrm{~min}$ ), PTH levels decreased within $1 \mathrm{~min}$ by $52 \%$ $(\mathrm{P}<0.01)$ with an initial $t_{1 / 2}$ of disappearance of $0.5 \mathrm{~min}$ and returned to basal levels after $10 \mathrm{~min}$. During the entire experiment $\mathrm{Ca}$ and $\mathrm{Ca}^{++}$were proportionally 

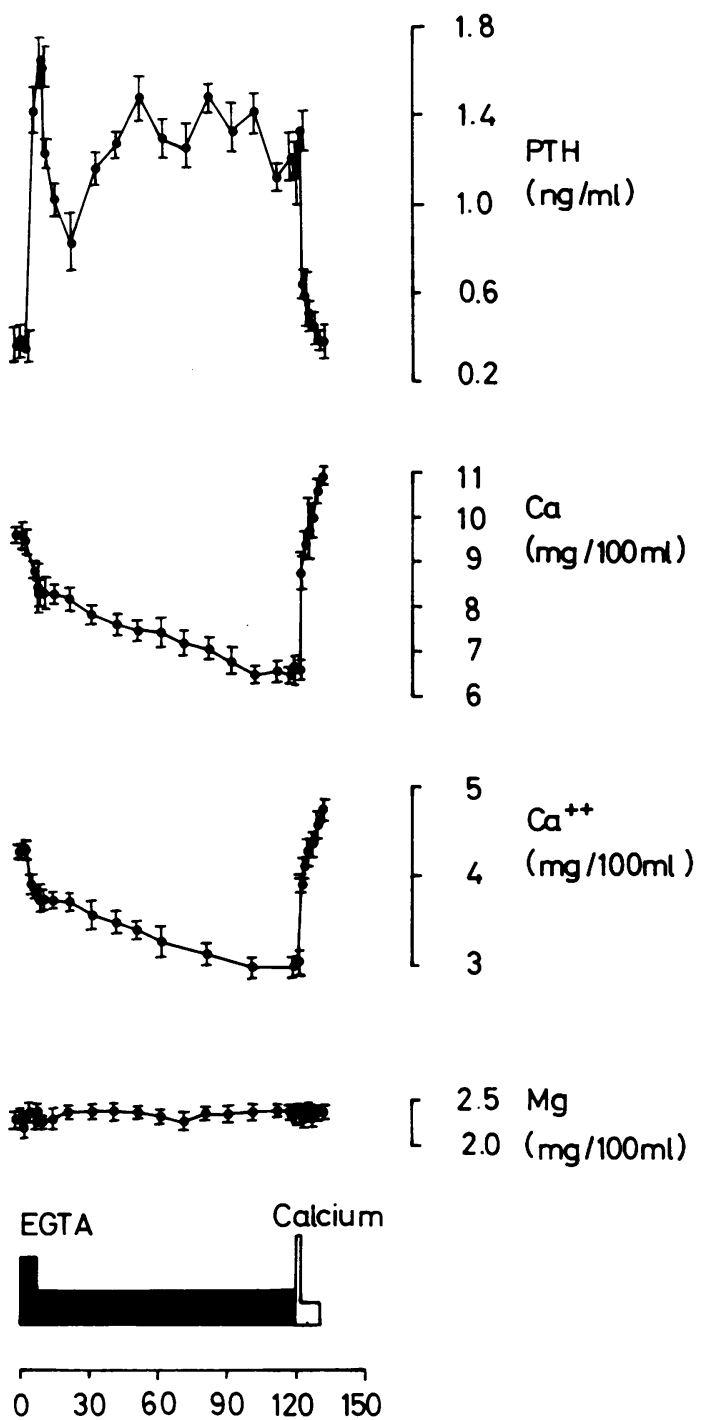

\section{Minutes}

FIGURE 1 Effects of EGTA (1.8 mg/kg per min, infused from 0 to $7 \mathrm{~min}$ and $0.9 \mathrm{mg} / \mathrm{kg}$ per min, infused up to $120 \mathrm{~min}$ ) and calcium $(2.8 \mathrm{mg} / \mathrm{kg}$ per min, infused from 120 to $121 \mathrm{~min}$ and $0.55 \mathrm{mg} / \mathrm{kg}$ per min, infused up to $130 \mathrm{~min}$ ) on PTH, $\mathrm{Ca}, \mathrm{Ca}^{++}$, and $\mathrm{Mg}$ levels. Each value represents the mean of five experiments. Significance of difference between basal levels of $\mathrm{Ca}, \mathrm{Ca}^{++}$, and PTH and corresponding mean concentrations at 6,7 , and $8 \mathrm{~min}$ and at 118,119 , and $120 \mathrm{~min}$, respectively: $P<0.001$. During calcium infusions $\mathrm{PTH}, \mathrm{Ca}$, and $\mathrm{Ca}^{++}$were significantly changed within $1 \mathrm{~min}(P<0.01)$.

changed $(r=0.99, P<0.001)$. The plasma Mg concentration was not altered.

Effect of epinephrine infusions on PTH levels (Fig. 2). During epinephrine infusions (lasting for $60 \mathrm{~min}$ ) PTH rapidly increased, then slowly returned to levels which, at the end of the infusions, were significantly lower $(P<0.001)$, than the $\Delta 6-8 \mathrm{~min}$ concentrations.

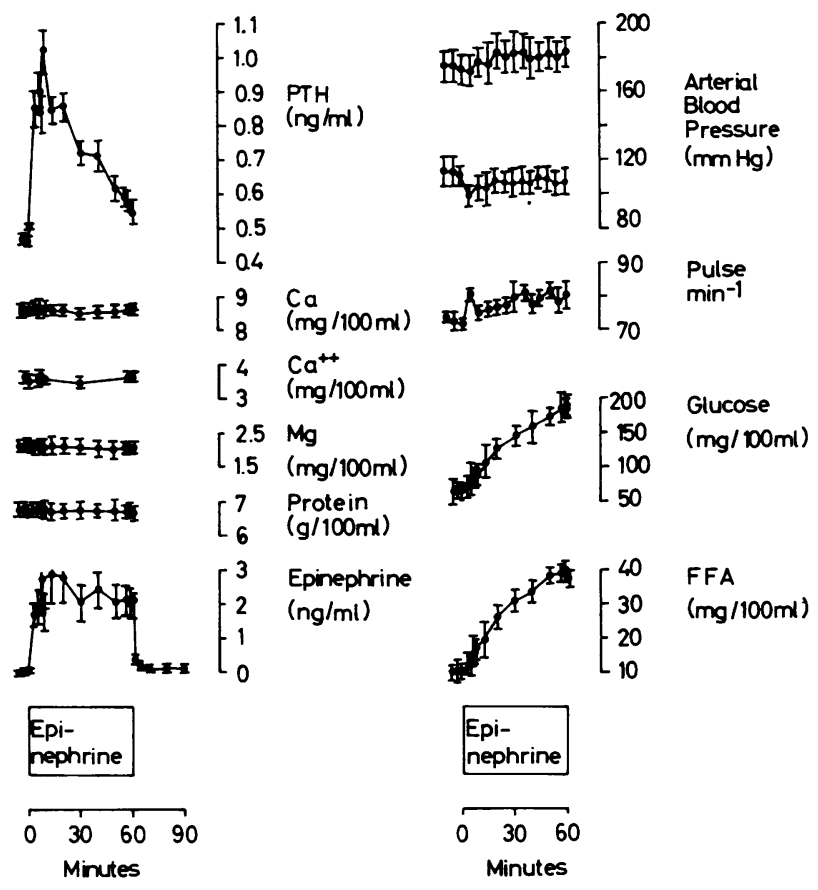

FIGURE 2 Effects of epinephrine $(0.07 \mu \mathrm{g} / \mathrm{kg}$ per min, infused from 0 to $60 \mathrm{~min}$ ) on $\mathrm{PTH}, \mathrm{Ca}, \mathrm{Ca}^{++}, \mathrm{Mg}$, protein, glucose, and FFA levels (each value representing the mean of eight experiments), on epinephrine levels, on blood pressure, and heart rate (each value representing the mean of four experiments). Significance of difference between basal levels and mean concentrations at 6,7 , and $8 \mathrm{~min}: P<0.001$ (for PTH and epinephrine), $P<0.05$ (for glucose and FFA). Mean concentrations at 58,59 , and $60 \mathrm{~min}$ of epinephrine, FFA, and glucose but not of PTH were significantly higher (P $<0.001$ ) than preinfusion concentrations.

$\mathrm{Ca}, \mathrm{Ca}^{++}, \mathrm{Mg}$ and proteins remained unchanged. As expected, the plasma epinephrine concentrations rapidly increased and remained elevated until the end of the experiments. After terminating the infusions, epinephrine decreased with an initial $t_{1 / 2}$ of disappearance of $1 \mathrm{~min}$ and reached basal concentrations within 5-10 min. Plasma norepinephrine and dopamine levels were not significantly altered (data not shown). FFA and glucose rapidly and almost linearly increased during the whole infusion time. Only minimal changes of systolic and diastolic blood pressure and heart rate were recorded.

Effect of repeated short-lasting epinephrine infusions on PTH levels (Fig. 3). Five epinephrine infusions (each lasting $7 \mathrm{~min}$ ) were administered at 30 -min intervals. PTH levels rapidly and reversibly increased during each infusion. However, while the $\Delta 6-8 \mathrm{~min}$ PTH responses to the first three infusions were similar, they were significantly smaller $(P<0.02)$ during infusions 4 and 5 than during infusions 1 and 2 . Ca and $\mathrm{Ca}^{++}$remained unchanged. $\mathrm{Mg}$ did not change during epinephrine infusions, although it tended to decrease 

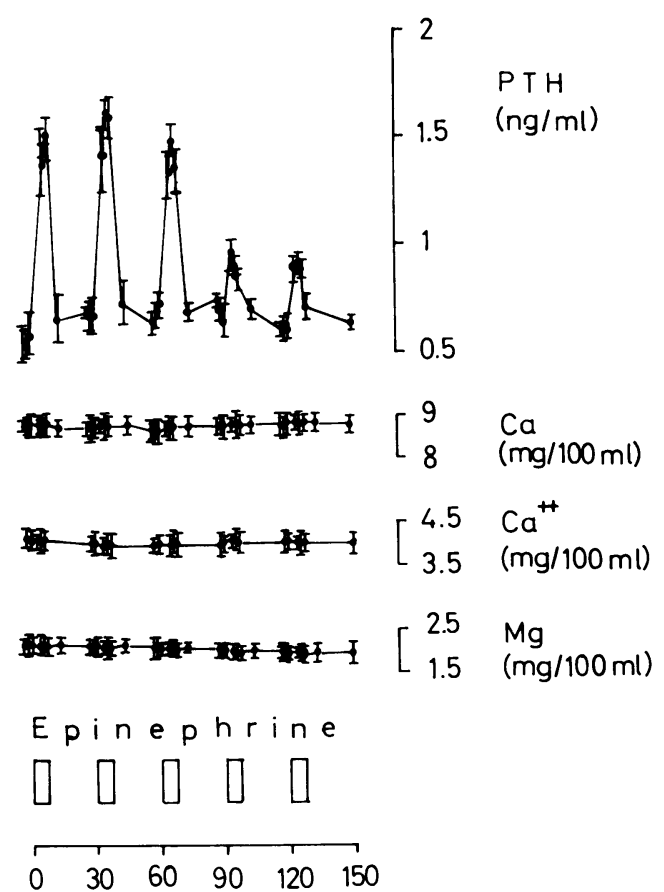

FIGURE 3 Effects of repeated epinephrine infusions (0.15 $\mu \mathrm{g} / \mathrm{kg}$ per $\mathrm{min}$ ) from 0 to 7,30 to 37,60 to 67,90 to 97 and 120 to 127 min on PTH, Ca, $\mathrm{Ca}^{++}$, and Mg levels. Each value represents the mean of six experiments. Significance of difference between basal levels and concentrations reached at 6,7 , and $8 \mathrm{~min}$ after the start of the five infusions: $P<0.05$. Significance of difference of $\Delta 6-8 \mathrm{~min}$ PTH responses to infusions from 90 to 97 and 120 to 127 , respectively, from infusions from 0 to 7 and 30 to $37 \mathrm{~min}$, respectively: $P<0.02$.

slightly but not significantly towards the end of the experiments.

Effect of isoproterenol infusions on PTH levels. (Table I). During isoproterenol infusions (lasting for 60 min) PTH rapidly increased, reaching peak values between 6 and $13 \mathrm{~min}$. PTH then returned to preinfusion levels toward the end of the infusions. During the first $8 \mathrm{~min}, \mathrm{Ca}, \mathrm{Ca}^{++}, \mathrm{Mg}$, and proteins remained unchanged but they were slightly decreased at the end of the infusions. In contrast to the transient PTH responses, FFA levels were continuously rising during the whole experiments. Only minimal changes of systolic and diastolic blood pressures were noted, while heart rates rapidly increased within the first 10 min by $17 \pm 5$ beats and then remained constantly elevated (not shown).

Effect of epinephrine infusions on PTH levels during hypocalcemia. Epinephrine was infused from 0-7 and 180-187, and EGTA from 90-188 min (Fig. 4). In response to the first epinephrine infusions from 0-7 min, PTH levels reversibly increased. EGTA-induced hypocalcemia from 90-188 min led to a sustained increase of PTH levels. When the second epinephrine in- fusions were superimposed from 180-187 $\mathrm{min}$ on the EGTA infusions, the PTH responses were two to six times higher $(P<0.02)$ than during the first epinephrine infusions when the animals were still normocalcemic. $\mathrm{Mg}$ remained constant during the experiments.

Effect of epinephrine infusions on PTH levels during maximal PTH responses to hypocalcemia. Epinephrine and EGTA was infused as indicated in the legend of Fig. 5. In response to the short-lasting infusions (for $7 \mathrm{~min}$ ) with epinephrine and with EGTA, starting at 0 and $90 \mathrm{~min}$, respectively, PTH levels were reversibly increased. During the prolonged EGTA infusions (starting at $210 \mathrm{~min}$ ) calcium decreased, while PTH rapidly increased and remained elevated. However, in spite of an additional rapid fall of plasma $\mathrm{Ca}$ and $\mathrm{Ca}^{++}$levels due to superimposed shortlasting EGTA infusions (from 270 to $277 \mathrm{~min}$ ), PTH levels did not increase further. On the other hand, a second epinephrine infusion (from 300 to $307 \mathrm{~min}$ ) induced a rapid and additional augmentation of the PTH levels which was not significantly different from that found during the first epinephrine infusion. Epinephrine infusions did not significantly change the concentration of $\mathrm{Ca}$ and $\mathrm{Ca}^{++}$. During the second short-lasting EGTA infusion (from 270 to $277 \mathrm{~min}$ ), the decrease of $\mathrm{Ca}^{++}$but not of $\mathrm{Ca}$ was somewhat more pronounced $(P<0.01)$ than during the first EGTA infusion (from 90 to $97 \mathrm{~min}$ ). $\mathrm{Mg}$ remained unchanged at all times during the experiment.

Effect of EGTA-induced hypocalcemia on PTH responses during infusions of epinephrine, isoproterenol, and propranolol. In the experiments reported on Table II, EGTA was infused twice for $7 \mathrm{~min}$ (from 0 to 7 and 180 to $187 \mathrm{~min}$ ), while epinephrine, isoproterenol, or propranolol were infused for $68 \mathrm{~min}$

TABLE I

Effects of 60-min Infusions with Isoproterenol*

\begin{tabular}{|c|c|c|c|}
\hline & Basal & $\Delta 6-8 \mathrm{~min}$ & $\Delta 58-60 \mathrm{~min}$ \\
\hline $\begin{array}{l}\text { PTH, } n g / m l \\
\mathrm{Ca}, m g / 100\end{array}$ & $0.62 \pm 0.16$ & $0.60 \pm 0.23 \ddagger$ & $-0.02 \pm 0.15$ \\
\hline & $8.84 \pm 0.25$ & $-0.09 \pm 0.07$ & $-0.17 \pm 0.05 \ddagger$ \\
\hline $\begin{array}{c}100 \mathrm{ml} \\
\mathrm{Mg}, \mathrm{mg} / 100\end{array}$ & $3.65 \pm 0.20$ & $-0.10 \pm 0.01$ & $-0.23 \pm 0.04 \ddagger$ \\
\hline & $2.39 \pm 0.04$ & $-0.04 \pm 0.00$ & $-0.12 \pm 0.02 \ddagger$ \\
\hline $\begin{array}{l}\text { Protein, } \\
\text { g/100 } \mathrm{ml} \\
\text { FFA, }\end{array}$ & $6.77 \pm 0.25$ & $-0.09 \pm 0.07$ & $-0.38 \pm 0.13 \ddagger$ \\
\hline$m g / 100 \mathrm{ml}$ & $4.8 .5 \pm 0.71$ & $5.37 \pm 2.15$ & $19.91 \pm 4.897$ \\
\hline
\end{tabular}

* $0.015 \mu \mathrm{g} / \mathrm{kg}$ per min.

\$ Statistically significant changes $(P<0.05)$ from basal levels (eight experiments). 

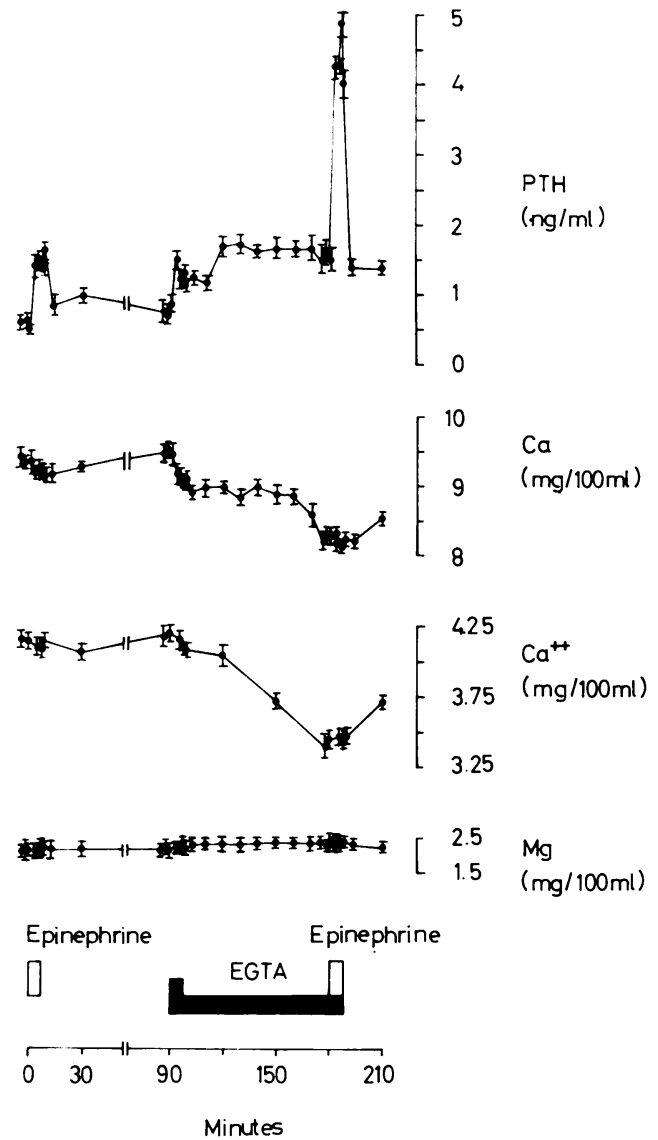

FigurE 4 Effect of epinephrine $(0.15 \mu \mathrm{g} / \mathrm{kg}$ per min $)$, infused alone from 0 to $7 \mathrm{~min}$ and combined from 180 to $187 \mathrm{~min}$ with EGTA $(0.7 \mathrm{mg} / \mathrm{kg}$ per min, infused from 90 to $97 \mathrm{~min}$ and $0.35 \mathrm{mg} / \mathrm{kg}$ per $\mathrm{min}$, infused up to $187 \mathrm{~min}$ ) on PTH, $\mathrm{Ca}, \mathrm{Ca}^{++}$, and $\mathrm{Mg}$ levels. Each value represents the mean of six experiments. Significance of difference of mean incremental changes of PTH at 6,7 , and $8 \mathrm{~min}$ after the start of the epinephrine infusions from 0 to $7 \mathrm{~min}(\Delta 6-8 \mathrm{~min}$ : 0.92 $\pm 0.22 \mathrm{ng} / \mathrm{ml}$ ) from those during epinephrine infusions from 180 to $187 \mathrm{~min}(\Delta 6-8 \mathrm{~min}: 2.76 \pm 0.54 \mathrm{ng} / \mathrm{ml}): P<0.02$. Infusions with EGTA led to a significant increase $(P<0.01)$ of PTH levels before the epinephrine infusions from 180 to $187 \mathrm{~min}$.

(from 120 to $188 \mathrm{~min}$ ). Propranolol was infused in amounts which completely suppressed the PTH responses to epinephrine (9; data not shown). Hypocalcemia induced by EGTA infusions (from 0 to $7 \mathrm{~min}$ ) caused rapid and reversible elevations of PTH levels. Subsequently ( $2 \mathrm{~h}$ later), epinephrine and isoproterenol were infused. Both compounds rapidly increased the PTH levels, which thereafter slowly returned towards preinfusion concentrations. On the other hand, during propranolol infusions, the PTH levels remained unaffected (data not shown). A second administration of EGTA (from 180 to $187 \mathrm{~min}$ ), superimposed on the infusions with epinephrine or isoproterenol, produced significantly higher elevations
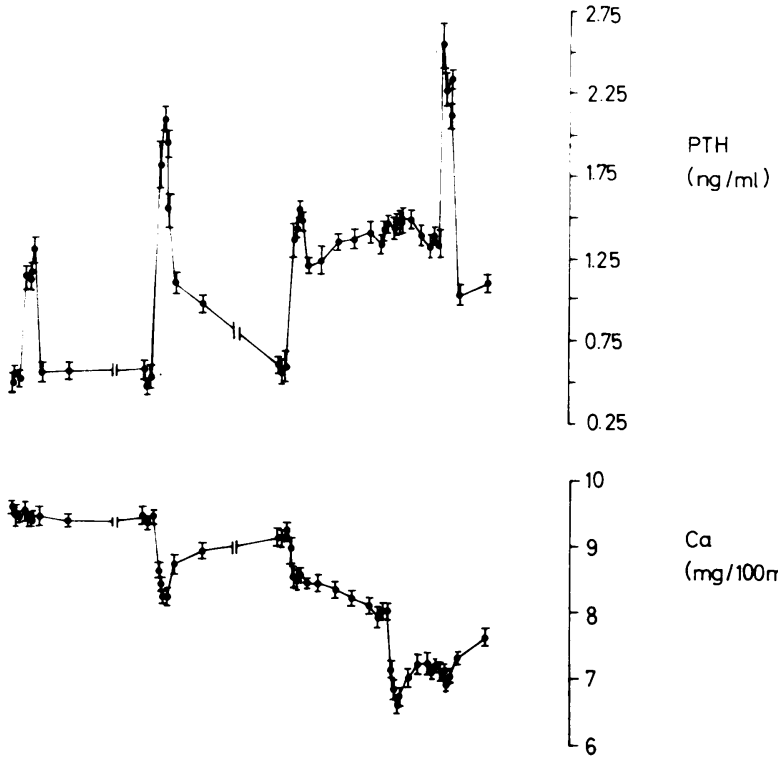

$\mathrm{Ca}$

$(\mathrm{mg} / 100 \mathrm{ml})$
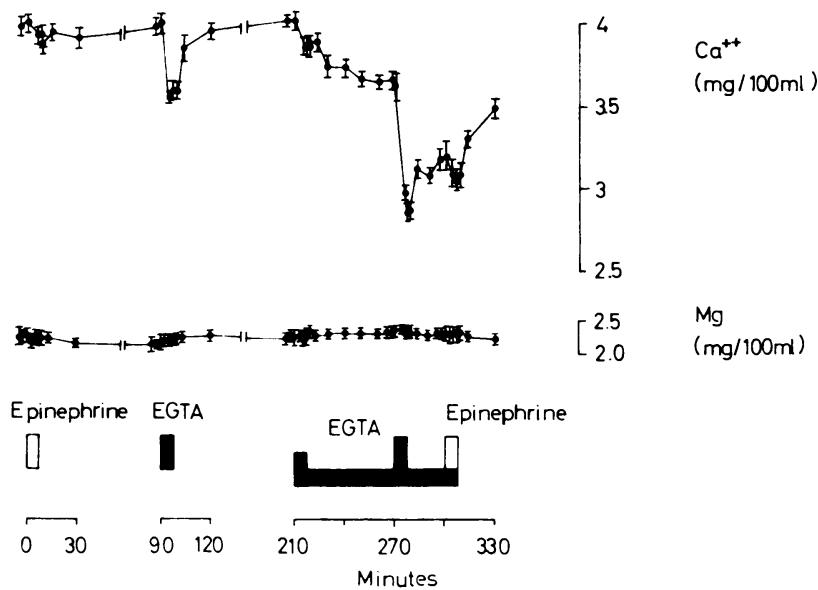

Figure 5 Effect of epinephrine $(0.15 \mu \mathrm{g} / \mathrm{kg}$ per min) and EGTA $(2.1 \mathrm{mg} / \mathrm{kg}$ per min), infused alone from 0 to 7 and 90 to $97 \mathrm{~min}$, respectively, and combined from 300 to 307 and 270 to $277 \mathrm{~min}$, respectively, with EGTA $(1.4 \mathrm{mg} / \mathrm{kg}$ per min, infused from 210 to $217 \mathrm{~min}$ and $0.7 \mathrm{mg} / \mathrm{kg}$ per min, infused up to $308 \mathrm{~min}$ ) on $\mathrm{PTH}, \mathrm{Ca}, \mathrm{Ca}^{++}$and $\mathrm{Mg}$ levels. Each value represents the mean of six experiments. Mean incremental changes of PTH at 6, 7, and 8 min after the start of the epinephrine infusions from 0 to $7 \mathrm{~min}$ were similar as those after the start of the epinephrine infusions from 300 to $307 \mathrm{~min}$. During the EGTA infusions from 90 to $97 \mathrm{~min}$, PTH increased $(\Delta 6-8 \mathrm{~min}: 1.28 \pm 0.29 \mathrm{ng} / \mathrm{ml}, P<0.01)$ but was not changed during EGTA infusions from 270 to $277 \mathrm{~min}$. Significance of difference of concentrations before the infusions with EGTA and epinephrine from 270 to 277 and 300 to $307 \mathrm{~min}$, respectively, from concentrations before the corresponding infusions from 0 to 7 and 90 to $97 \mathrm{~min}$, respectively: $P<0.05$ (for PTH); $P<0.001$ (for $\mathrm{Ca}$ and $\mathrm{Ca}^{++}$).

of PTH levels $(P<0.02)$ than those found during the initial EGTA infusions (from 0 to $7 \mathrm{~min}$ ), although serum ionized and total calcium levels were decreased to the same extent or less. On the other hand, pro- 
TABLE II

Effects of Epinephrine, Isoproterenol and Propranolol on PTH Responses to Hypocalcemia

\begin{tabular}{|c|c|c|c|}
\hline & EGTA 0-7 min & $\begin{array}{c}\text { Epinephrine } \\
\text { 120-188 min* } \\
+ \text { EGTA } \\
180-187 \text { min }\end{array}$ & $P \downarrow$ \\
\hline $\begin{array}{l}\mathrm{PTH}, n g / m l \\
\mathrm{Ca}, m g / 100 m l \\
\mathrm{Ca}^{++}, m g / 100 m l \\
\mathrm{Mg}, m g / 100 m l\end{array}$ & $\begin{array}{c}1.03 \pm 0.21^{\prime \prime} \\
-0.88 \pm 0.08 \rrbracket \\
-0.36 \pm 0.08^{\prime \prime} \\
-0.01 \pm 0.03\end{array}$ & $\begin{array}{c}1.93 \pm 0.28^{\prime \prime} \\
-0.83 \pm 0.18^{\prime \prime} \\
-0.29 \pm 0.03^{\prime \prime} \\
-0.03 \pm 0.00 \\
\\
\text { Isoproterenol } \\
120-188 \mathrm{~min}^{*} \\
+ \text { EGTA } \\
180-187 \mathrm{~min}\end{array}$ & $\begin{array}{c}<0.001 \\
\text { NS } \\
\text { NS } \\
\text { NS }\end{array}$ \\
\hline $\begin{array}{l}\mathrm{PTH}, n g / m l \\
\mathrm{Ca}, m g / 100 m l \\
\mathrm{Ca}^{++}, m g / 100 m l \\
\mathrm{Mg}, m g / 100 m l\end{array}$ & $\begin{array}{c}0.87 \pm 0.18 \\
-1.21 \pm 0.09 \rrbracket \\
-0.50 \pm 0.069 \\
0.00 \pm 0.00\end{array}$ & $\begin{array}{c}2.06 \pm 0.56^{\prime \prime} \\
-0.95 \pm 0.11 \rrbracket \\
-0.44 \pm 0.089 \\
0.01 \pm 0.00 \\
\text { Propranolol } \\
120-188 \mathrm{~min}^{*} \\
+ \text { EGTA } \\
180-187 \mathrm{~min}\end{array}$ & $\begin{array}{c}<0.02 \\
<0.005 \\
\text { NS } \\
\text { NS }\end{array}$ \\
\hline $\begin{array}{l}\mathrm{PTH}, n g / m l \\
\mathrm{Ca}, m g / 100 m l \\
\mathrm{Ca}^{++}, m g / 100 m l \\
\mathrm{Mg}, m g / 100 m l\end{array}$ & $\begin{array}{r}0.62 \pm 0.16 \S \\
-1.07 \pm 0.14 \uparrow \\
-0.44 \pm 0.07 " \\
0.01 \pm 0.02\end{array}$ & $\begin{array}{c}0.67 \pm 0.14^{\prime \prime} \\
-1.23 \pm 0.179 \\
-0.58 \pm 0.11^{\prime \prime} \\
0.01 \pm 0.01\end{array}$ & $\begin{array}{l}\text { NS } \\
\text { NS } \\
\text { NS } \\
\text { NS }\end{array}$ \\
\hline
\end{tabular}

Basal concentrations of PTH, Ca, $\mathrm{Ca}^{++}$, and $\mathrm{Mg}$ before EGTA infusions (from 180-187 min) were not significantly different from those before EGTA infusions (from 0-7 min) and basal levels before epinephrine, isoproterenol, and propranolol infusions (from 120-188 $\mathrm{min}$ ).

* The effect of epinephrine $(0.07 \mu \mathrm{g} / \mathrm{kg}$ per $\mathrm{min})$ and isoproterenol $(0.015 \mu \mathrm{g} / \mathrm{kg}$ per min) was studied in eight animals, of propranolol $(30 \mu \mathrm{g} / \mathrm{kg}$ per min) in six animals.

† Significance of difference between $\Delta 6$-8- and $\Delta$ 186-188min changes.

Significance of $\Delta 6-8$-min changes from basal concentrations: $\$ P<0.05 ; " ~ P<0.01 ;$ I $P<0.001$; no symbol, $P>0.05$.

pranolol, when combined with EGTA (from 180 to 187 $\mathrm{min}$ ), was unable to modulate the PTH responses to the second EGTA infusions.

Effect of EGTA-induced hypocalcemia in animals lacking a PTH response after prolonged epinephrine infusions. Epinephrine and EGTA were infused as indicated in the legend of Fig. 6. In response to the first epinephrine infusions (from 0 to $7 \mathrm{~min}$ ), the PTH levels rapidly increased and reached basal levels again by $30 \mathrm{~min}$. PTH responded similarly to subsequent epinephrine infusions starting at $60 \mathrm{~min}$. However, the level of the hormone decreased with time in spite of the continuous epinephrine administration, reaching preinfusions concentrations after 50-60 min. When the amount of epinephrine was doubled between 120 and $127 \mathrm{~min}$ and during the subsequent prolonged epineph- rine infusions lasting up to $150 \mathrm{~min}$, PTH levels remained unchanged. On the other hand, a small level of hypocalcemia obtained by EGTA infusions which were superimposed on the epinephrine infusions, always caused rapid and important elevations of the PTH
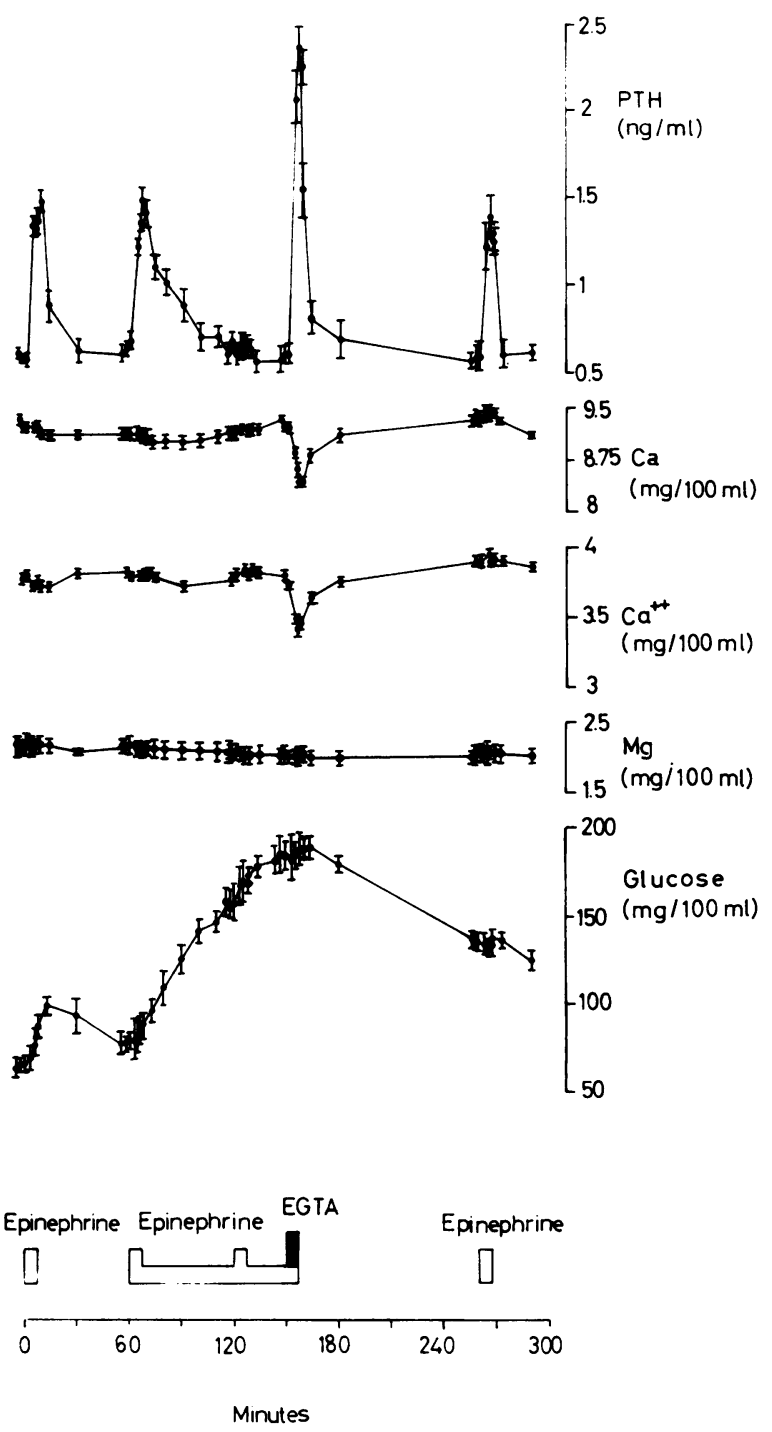

FIGURE 6 Effects of epinephrine $(0.15 \mu \mathrm{g} / \mathrm{kg}$ per $\mathrm{min}$, infused from 0 to 7,60 to 67,120 to 127 and 260 to $267 \mathrm{~min}$ and $0.07 \mu \mathrm{g} / \mathrm{kg}$ per min, infused from 67 to 120 and 127 to $157 \mathrm{~min}$ ) and of EGTA (1.8 mg/kg per min, combined from 150 to $157 \mathrm{~min}$ with epinephrine infusions) on $\mathrm{PTH}, \mathrm{Ca}, \mathrm{Ca}^{++}$, $\mathrm{Mg}$, and glucose levels. Each value represents the mean of eight experiments. Mean incremental changes of PTH at 6 , 7 , and $8 \mathrm{~min}$ after the start of 7 -min infusions with epinephrine, starting at 0,60 , and $260 \mathrm{~min}$ were comparable $(\Delta 6-8 \mathrm{~min}$ : $0.94 \pm 0.32 ; 0.80 \pm 0.21 ; 0.74 \pm 0.29 \mathrm{ng} / \mathrm{ml}$ ) and significantly different from preinfusion concentrations $(P<0.05)$. PTH levels did not change during epinephrine infusions from 120 to $127 \mathrm{~min}$. Significance of difference of basal levels from mean PTH concentrations at 6,7 , and 8 min during hypocalcemia due to EGTA infusions from 150 to $157 \mathrm{~min}: P<0.01$. 
levels. At $260 \mathrm{~min}$, e.g. $>100 \mathrm{~min}$ after the end of the last epinephrine infusions, the PTH responses to epinephrine were restored. Glucose was transiently increased up to $13 \mathrm{~min}$ in response to the first epinephrine infusions (from 0 to $7 \mathrm{~min}$ ). Subsequent epinephrine infusions (from 60 to $158 \mathrm{~min}$ ), at variance with the transient PTH response, induced a continuous and constant increase of glucose levels. After interruption of the epinephrine infusions, the glucose concentration slowly declined for the next $100 \mathrm{~min}$ but remained higher than at $60 \mathrm{~min}$ after the beginning of the experiments. When epinephrine was infused from 260 to $267 \mathrm{~min}$, glucose, in contrast to PTH, remained stable. $\mathrm{PTH}, \mathrm{Ca} \mathrm{Ca}^{++}$, and $\mathrm{Mg}$ levels remained unchanged before the repetitive 7-min epinephrine and EGTA infusions, starting at $0,60,120,260$, and $150 \mathrm{~min}$, respectively. $\mathrm{Ca}, \mathrm{Ca}^{++}$, and $\mathrm{Mg}$ concentrations were not significantly altered during the epinephrine infusions.

\section{DISCUSSION}

The present results extend our previous studies, in which we demonstrated increased PTH levels occuring within seconds during infusions with EGTA and when the EGTA-induced hypocalcemia was still in the physiological range (6). This study shows that during prolonged hypocalcemia, the initial rapid increase of PTH levels (acute response), after a transient decrease, is followed by a gradual and sustained rise of the hormone (late response), suggesting a bi- or multiphasic release process similar to the one shown for other hormones during stimulation by appropriate agents (35-39). Multiphasic response patterns of PTH during hypocalcemia have been noted occasionally but not consistently in previous investigations (3, 4). Our findings further support the notion that simple linear relationships between plasma calcium and PTH concentrations do not exist $(6,8)$. Since PTH has been measured in peripheral plasma samples, the concentration of the metabolic alteration of the secreted PTH peptide(s) could not be assessed. However, our data presumably reflect secretory responses of the parathyroid glands, since hypocalcemia elevated and calcium infusions suppressed PTH levels within minutes.

When the PTH responses during EGTA-induced hypocalcemia are compared with those occurring during stimulation with epinephrine and isoproterenol, considerable differences are observed. As we have previously reported (9), PTH also increased within a few min during epinephrine and isoproterenol infusions. However, in contrast to the constantly elevated PTH levels measured during hypocalcemia, the PTH levels gradually fell towards preinfusion concentrations at the end of the 60-min epinephrine or isoproterenol infusions, suggesting that only a part of the PTH present in the parathyroid glands was released. Even when the amount of epinephrine infused was doubled at $60 \mathrm{~min}$, PTH levels remained unchanged, indicating that the parathyroid glands were no longer responding to the catecholamine. This finding is supported by the fact that PTH responses decreased when epinephrine was repeatedly infused at 30 -min intervals. The data indicate that the parathyroid glands became refractory during prolonged or repeated exposition to epinephrine or isoproterenol. Similar findings have been reported in in vitro studies, in which parathyroid glands or cells have been used $(15,16)$. Full responsiveness to epinephrine returned again after the discontinuation of the epinephrine infusions for at least $100 \mathrm{~min}$. This suggests that the stimulability is at least partially determined by the time of the last exposure to epinephrine.

The fact that plasma epinephrine levels reached during epinephrine infusions were in the range of those found after insulin-induced hypoglycemia in man (40), and the fact that during these infusions, both the heart rate and the blood pressure were only slightly altered, suggests that the amounts of epinephrine administered were probably in the physiological range.

Plasma glucose and PTH response patterns to epinephrine were quite different when the stimulation occured at appropriate time intervals. PTH responses were rapid but never sustained, whereas the hyperglycemic responses were gradual and persisted for longer time periods than the PTH responses. On the other hand, epinephrine became ineffective in raising the plasma glucose levels at a time when the stimulability of parathyroid glands had returned to normal. This indicates that the activation of the cascade of events leading to the hyperglycemic response (41) exhibits obvious differences in its time-course to epinephrine infusions when compared with the release pattern of PTH.

The reason for the apparent resistance of the parathyroid glands to $\beta$-adrenergic agonists may involve one or several factors. A decreasing responsiveness could be due to metabolic inactivation of epinephrine and isoproterenol. However, there was a sustained elevation of the plasma levels during the epinephrine infusions and epinephrine did not fall before the infusions were stopped. Furthermore, during infusions with isoproterenol, heart rates, in contrast to PTH levels, remained elevated for the entire duration of the experiments, suggesting that isoproterenol retained its pharmacological activity at least in cardiac tissue. Also, the almost linear increase of plasma glucose and(or) FFA levels during the 60-min epinephrine or isoproterenol infusions, at variance with the transient increase of the PTH levels, reflected the expected pharmacological responses $(18,19)$. These data exclude metabolic inactivation of epinephrine or isoproterenol 
as a cause of the resistance of the parathyroid glands to $\beta$-adrenergic stimulation. A decrease of PTH levels could, however, be due to an elevation of plasma $\mathrm{Ca}^{++}$ or $\mathrm{Mg}$ concentrations $(1,2,8)$, or, as we have previously reported (9), PTH responses to epinephrine could be abolished during hypercalcemia. However, during prolonged epinephrine and isoproterenol infusions, $\mathrm{Ca}^{++}$, $\mathrm{Ca}$, and $\mathrm{Mg}$ concentrations did not increase. Therefore, the secondary decline of PTH levels during epinephrine and isoproterenol infusions observed in this study was not due to a direct or indirect effect of $\mathrm{Ca}^{++}$ and $\mathrm{Mg}$ on PTH levels. It can be concluded that the sensitivity of the parathyroid glands to $\beta$-adrenergic stimulation was altered during prolonged or repetitive stimulation. Recent in vitro studies have demonstrated that the release of PTH by epinephrine and isoproterenol is mediated by $\beta$-adrenergic receptors localized on parathyroid cells, whose stimulation through activation of adenylyl cyclase leads to generation of cyclic adenosine $3^{\prime}, 5^{\prime}$-monophosphate and to PTH release (16). During a prolonged administration of isoproterenol, cAMP levels were raised and PTH levels remained unchanged. These experiments suggest that the resistance to $\beta$-adrenergic stimulation is not linked to cAMP formation but rather to an effect beyond cAMP stimulation, such as an alteration of the activity of protein kinases. Apparently, resistance of parathyroid glands to $\beta$-adrenergic stimulation is not associated with a fall of beta-adrenergic binding sites, paralleled by a reduction of adenylyl cyclase activity and reduced generation of cAMP, as has been shown for the pineal gland and for frog erythrocytes $(42,43)$.

Resistance of parathyroid glands at least to epinephrine could be based on an $\alpha$-receptor mediated inhibition or desensitization (44). However, since our own studies show, that $\alpha$-adrenergic agonists are ineffective in changing PTH levels in cows, ${ }^{2}$ such a mechanism appears unlikely.

The absent responsiveness of parathyroid glands after prolonged exposure to epinephrine remains to be further clarified. Interestingly, pheochromocytomas are rarely associated with hyperparathyroidism (4548), unless the patients suffer from genetically determined familial polyendocrine adenomatosis type 2 (49).

The present data demonstrate that the PTH response to a hypocalcemia is quite different from the response obtained by $\beta$-adrenergic stimulation. Our results indicate that the levels of circulating PTH were independently modulated by variations of the plasma concentrations of calcium and of $\beta$-adrenergic agonists. Epinephrine infusions in severely hypocalcemic animals increased the PTH levels within minutes, when additional infusions with EGTA, rendering the animals more hypocalcemic, were ineffective. At the end of

${ }^{2}$ Manuscript in preparation. prolonged infusions with epinephrine, when additional infusions with epinephrine did not increase PTH levels further, EGTA-induced hypocalcemia consistently increased PTH concentrations within minutes. From these experiments, it appears that EGTA-induced hypocalcemia and $\beta$-adrenergic agonists release PTH by two different mechanisms.

A valid argument for the existence of separate mechanisms inducing the release of PTH may be advanced on the basis of the demonstrated differential effect of $\beta$-adrenergic blockade upon the acute PTH responses to hypocalcemia and epinephrine. The $\beta$-adrenergic blocker propranolol was infused in amounts sufficient to suppress the epinephrine-stimulated PTH responses completely. Under these conditions, the hypocalcemiastimulated increase of PTH levels was not affected. Similar findings have been reported in rats (11). The conclusion thus seems to be that hypocalcemia and epinephrine initially stimulate the release of PTH by two different triggering mechanisms. In accordance, findings have been reported $(11,16)$ suggesting that the PTH responses to $\beta$-adrenergic agonists and to low plasma calcium concentrations are probably not mediated by the same receptors. However, a final common pathway could still exist.

The fact that the blockade of $\beta$-adrenergic receptors by propranolol does not modify basal PTH levels indicates that the parathyroid function in cows (but apparently not in man and rats $[10,11]$ ), is normally not under a $\beta$-adrenergic tone. Also, propranolol added to bovine parathyroid cells could not consistently inhibit the release of PTH (16). This suggests that true species differences may exist.

Although our data indicate that variations of the extracellular calcium concentrations and $\beta$-adrenergic agonists modify PTH levels by two different and independent mechanisms, evidence is also presented that the two mechanisms may operate under particular conditions by modulating the effects of each other. Thus, an EGTA-induced hypocalcemia rendered the parathyroid glands more sensitive to a stimulation with $\beta$ adrenergic agonists. The increased responsiveness of PTH to epinephrine was only observed during a mild hypocalcemia, while during a more severe hypocalcemia the rise of PTH levels caused by epinephrine was similar to that occuring during normocalcemia. Together with previously published experiments, in which we showed a suppression of epinephrine-stimulated PTH responses during hypercalcemia (9) the present data suggest an optimal range of plasma calcium concentrations for the stimulability of PTH release by $\beta$-adrenergic agonists. Whereas the magnitude of the acute PTH response to epinephrine was partially determined by the concentration of the plasma calcium at the moment of the $\beta$-adrenergic stimulation, infusions of epinephrine or isoproterenol enhanced the 
acute PTH response to EGTA-induced hypocalcemia at a time when $\beta$-adrenergic agonists alone were no longer effective in increasing PTH levels.

\section{ACKNOWLEDGMENTS}

We thank Prof. Dr. H. Spörri and Dr. M. Becker, School of Veterinary Medicine, University of Zurich, for advice given in electrocardiogram and blood pressure studies. Experimental animals were kindly provided by Prof. Dr. M. Berchtold, School of Veterinary Medicine, University of Zurich and Prof. Dr. F. Weber, Department of Animal Production, Federal Institute of Technology, Zurich. The excellent technical assistance of Miss B. Amey, Miss U. Flueles, Mrs. P. Graf-Buschmann, Mrs. M. Gassmann-Boller, Miss H. Schreier, and Miss M. Schulz is gratefully acknowledged.

This work was supported by the Swiss National Science Foundation (grant 3.773.76) and the "Sandozstiftung zur Förderung der medizinisch-biologischen Wissenschaften”.

\section{REFERENCES}

1. Sherwood, L. M., J. T. Potts, Jr., A. D. Care, G. P. Mayer, and G. D. Aurbach. 1966. Evaluation by radioimmunoassay of factors controlling the secretion of parathyroid hormone. Intravenous infusions of calcium and ethylenediamine tetraacetic acid in the cow and goat. Nature (Lond.). 209: 52-55.

2. Care, A. D., L. M. Sherwood, J. T. Potts, Jr., G. P. Mayer, and G. D. Aurbach. 1966. Perfusions of isolated parathyroid gland of the goat and sheep. Nature (Lond.). 209: $55-57$.

3. Sherwood, L. M., G. P. Mayer, C. F. Ramberg, Jr., D. S. Kronfeld, G. D. Aurbach, and J. T. Potts, Jr. 1968. Regulation of parathyroid hormone secretion: proportional control by calcium, lack of effect of phosphate. Endocrinology. 83: 1043-1051.

4. Ramberg, C. F., Jr., G. P. Mayer, D. S. Kronfeld, G. D. Aurbach, L. M. Sherwood, and J. T. Potts, Jr. 1967. Plasma calcium and parathyroid hormone responses to EDTA infusions in the cow. Am. J. Physiol. 213: 878-882.

5. Fischer, J. A., U. Binswanger, and J. W. Blum. 1973. The acute parathyroid hormone response to changes in ionized calcium during phosphate infusions in the cow. Eur. J. Clin. Invest. 3: 151-15.5.

6. Blum, J. W., J. A. Fischer, D. Schwoerer, W. Hunziker, and U. Binswanger. 1974. Acute parathyroid hormone response: sensitivity, relationship to hypocalcemia, and rapidity. Endocrinology. 95: 753-759.

7. Mayer, G. P., C. F. Ramberg, D. S. Kronfeld, R. M. Buckle, L. M. Sherwood, G. D. Aurbach, and J. T. Potts, Jr. 1969. Plasma parathyroid hormone concentration in hypocalcemic parturient cows. Am. J. Vet. Res. 30: 1587-1597.

8. Blum, J. W., G. P. Mayer, and J. T. Potts, Jr. 1974. Parathyroid hormone responses during spontaneous hypocalcemia and induced hypercalcemia in cows. Endocrinology. 95: 84-92.

9. Fischer, J. A., J. W. Blum, and U. Binswanger. 1973. Acute parathyroid hormone response to epinephrine in vivo. J. Clin. Invest. 52: 2434-2440.

10. Kukreja, S. C., G. K. Hargis, E. N. Bowser, W. J. Henderson, E. W. Fisherman, and G. A. Williams. 1975. Role of adrenergic stimuli in parathyroid hormone secretion in man. J. Clin. Endocrinol. Metab. 40: 478-481.

11. Kukreja, S. C., P. A. Johnson, G. Ayala, P. Banerjee, E. N. Bowser, G. K. Hargis, and G. A. Williams, 1976. Role of calcium and beta-adrenergic system in control of parathyroid hormone secretion. Proc. Soc. Exp. Biol. Med. 151: $326-328$.

12. Mayer, G. P., J. A. Barto, J. A. Keaton, and M. P. Moore 1976. Effect of epinephrine on parathyroid hormone (PTH) secretion in vivo. 5th International Congress of Endocrinology. Hamburg. 229. (Abstr.)

13. Abe, M., and L. M. Sherwood. 1972. Regulation of parathyroid hormone secretion by adenyl cyclase. Biochem. Biophys. Res. Commun. 48: 396-401.

14. Williams, G. A., G. K. Hargis, E. N. Bowser, W. J. Henderson, and N. J. Martinez. 1973. Evidence for a role of adenosine $3^{\prime}, 5^{\prime}$-monophosphate in parathyroid hormone release. Endocrinology. 92: 687-691.

15. Birnbaumer, M. E., A. B. Schneider, and L. M. Sherwood. 1975. "Perifusion" of the parathyroid glands: an approach to the kinetics of hormone storage and secretion. 57th Annual Meeting, Endocrine Society, New York. 198. (Abstr.)

16. Brown, E. M., S. Hurwitz, and G. D. Aurbach. 1977. Beta-adrenergic stimulation of cyclic AMP content and parathyroid hormone release from isolated bovine parathyroid cells. Endocrinology. 100: 1696-1702.

17. Brown, E. M., S. Hurwitz, C. J. Woodard, and G. D. Aurbach. 1977. Direct identification of beta-adrenergic receptors on isolated parathyroid cells. Endocrinology. 100: $1703-1709$.

18. Innes, I. R., and M. Nickerson. 1975. Norepinephrine, epinephrine, and the sympathomimetic amines. In The Pharmacological Basis of Therapeutics. L. S. Goodman, and A. Gilman, editors. MacMillan Publishing Co., Inc., New York, 5th edition. 497-513.

19. Pilkington, T. R. E., R. D. Lowe, R. Foster, B. F. Robinson, and A. Antonis. 1966. Effect of sympathomimetic compounds with beta-adrenergic effects on plasma free fatty acids in man. J. Lipid Res. 7: 73-76.

20. Neil, E. 1975. Catecholamines and the cardiovascular system. Hand. Physiol. 7 (Endocrinology; Adrenal Gland): $473-489$.

21. Ganong, W. F. 1974. The role of catecholamines and acetylcholine in the regulation of endocrine function. Life Sci. 15: 1401-1414.

22. Rasmussen, H. 1970. Cell communication, calcium ion, and cyclic adenosine monophosphate. Science (Wash. D. C.). 170: 4()4-412.

23. Birnbaumer, L. 1973. Hormone-sensitive adenylyl cyclase. Useful models for studying hormone receptor functions in cell-free systems. Biochim. Biophys. Acta. 300: $129-158$.

24. Steer, M. L., and A. Levitzki. 1975. The control of adenylate cyclase by calcium in turkey erythrocyte ghosts. J. Biol. Chem. 250: 2080-2084.

25. Brostrom, C. O., Y. C. Huang, B. M. Beckenridge, and D. J. Wolff. 1975. Identification of a calcium-binding protein as a calcium-dependent regulator of brain adenylate cyclase. Proc. Natl. Acad. Sci. U. S. A. 72: 64-68.

26. Kakiuchi, S., R. Yamazaki, Y. Teshima, and U. Uenishi. 1973. Regulation of nucleoside cyclic $3^{\prime}, 5^{\prime}$-monophosphate phosphodiesterase activity from rat brain by a modulator and Ca ${ }^{++}$. Proc. Natl. Acad. Sci. U. S. A. 70: $3526-2530$.

27. Azhar, S., and K. M. J. Menon. 1977. Cyclic nucleotide phosphodiesterase from rat anterior pituitary. Characterization of multiple forms and regulation by protein activator and $\mathrm{Ca}^{2+}$. Eur. J. Biochem. 73: 73-82.

28. Spörri, H. 1976. Blutkreislauf. In Lehrbuch der Veterinärphysiologie. A. Scheunert, and A. Trautmann, editors. Paul Parey, Berlin. 6th edition, 467-591. 
29. Becker, M. 1977. Eine Methode des arteriellen Zugangs beim Rind. Schweiz. Arch. Tierheilkde. 119: 193-195.

30. Schreiber, J., and R. Lachenicht. 1973. Bestimmung der Glucose nach der GOD-Perid-Methode mit dem Technicon SMA 6/60. Z. Klin. Chem. Klin. Biochem. 11: 31-34.

31. Falholt, K., B. Lund, and W. Falholt. 1973. An easy colorimetric micro-method for routine determination of free fatty acids in plasma. Clin. Chim. Acta. 46: 103-111.

32. Doumas, B. T. 1975. Standards for total protein assays - a collaborative study. Clin. Chem. 21: 1159-1166.

33. Da Prada, M., and G. Zürcher. 1976. Simultaneous radioenzymatic determination of plasma and tissue adrenaline, noradrenaline and dopamine within the femtomole range. Life Sci. 19: 1161-1174.

34. Croxton, E. F. 1959. Elementary Statistics with Applications in Medicine and the Biological Sciences. Dover Publications, Inc., New York. 2nd edition. 376 pp.

35. Sachs, H., L. Share, J. Osinchak, and A. Carpi. 1967. Capacity of the neurohypophysis to release vasopressin. Endocrinology. 81: 755-770.

36. Cerasi, E., and R. Luft. 1967. Plasma insulin response to glucose infusion in healthy subjects and in diabetes mellitus. Acta Endocrinol. 55: 278-304.

37. Curry, D. L., L. L. Bennett, and G. M. Grodsky. 1966. Dynamics of insulin secretion by the perfused rat pancreas. Endocrinology. 83: 572-584.

38. Assan, R., J. Boillot, J. R. Attali, E. Soufflet, and G. Bellerio. 1972. Diphasic glucagon release induced by arginine in the perfused rat pancreas. Nature (Lond.). 239: 125-126.

39. Bremner, W. J., and A. Paulsen. 1974. Two pools of lutenizing hormone in the human pituitary: evidence from constant administration of luteinizing hormonereleasing hormone. J. Clin. Endocrinol. Metab. 39: $811-815$.

40. Christensen, N. J., K. G. M. M. Alberti, and O. Brandsborg. 1975. Plasma catecholamines and blood substrate concentrations: studies in insulin induced hypoglycemia and after adrenaline infusions. Eur. J. Clin. Invest. 5: 415-423.

41. Löffler, G. 1975. Stoffwechsel der Kohlehydrate. In Physiologische Chemie. H. A. Harper, G. Löffler, P. E. Petrides, and L. Weiss, editors. Springer Verlag, Berlin. 1st edition. 289-320.

42. Kebabian, J. W., M. Zatz, J. A. Romero, and J. Axelrod. 1975. Rapid changes in rat-pineal beta-adrenergic receptor: alterations in $\left[{ }^{3} \mathrm{H}\right]$ alprenolol binding and adenyl cyclase. Proc. Natl. Acad. Sci. U.S.A. 72: 3735-3739.

43. Mukherjee, C., M. C. Caron, and R. J. Lefkowitz. 1975. Catecholamine induced subsensitivity of adenylate cyclase associated with loss of beta-adrenergic receptor binding sites. Proc. Natl. Acad. Sci. U.S.A. 72: 1945- 1949.

44. Strittmatter, W. J., J. N. Davis, and R. J. Lefkowitz. 1977. Alpha-adrenergic receptors in rat parotid cells. J. Biol. Chem. 252: 5478-5482.

45. Kukreja, S. C., G. K. Hargis, I. M. Rosenthal, and G. A. Williams. 1973. Pheochromocytoma causing excessive parathyroid hormone production and hypercalcemia. Ann. Intern. Med. 79: 838-840.

46. Swinton, N. W., Jr., E. P. Clerkin, and L. D. Flint. 1972 Hypercalcemia and familial pheochromocytoma. Correction after adrenalectomy. Ann. Intern. Med. 76: 455-457.

47. Miller, S. S., G. W. Sizemore, S. G. Sheps, and G. M Tyce. 1975. Parathyroid function in patients with pheochromocytoma. Ann. Intern. Med. 82: 372-375.

48. Gray, R. S., and J. Gillon. 1976. Normotensive phaeochromocytoma with hypercalcemia: correction after adrenalectomy. Br. Med.J. 1: 378 .

49. Steiner, A. L., A. D. Goodman, and S. R. Powers. 1968. Study of a kindred with pheochromocytoma, medullary thyroid carcinoma, hyperparathyroidism and Cushing's disease: multiple endocrine neoplasia, Type 2. Medicine (Baltimore). 47: 371-409. 